\title{
HUBUNGAN INTERAKSI SOSIAL DENGAN PEKEMBANGAN ANAK DI PAUD NUSA MANDIRI SATU KABUPATEN SUKABUMI (STUDI ANTARA ANAK AUTIS DENGAN ANAK PASIF)
}

\author{
Siti Juariyah ${ }^{1}$, Supardi ${ }^{2(*)}$ \\ Universitas Panca Sakti Bekasi, Indonesia ${ }^{12}$ \\ sitijuariyah@gmail.com ${ }^{1}$, supardi.hamka@gmail.com²
}

\begin{tabular}{ll}
\hline & \\
Received: & 23 Agustus 2021 \\
Revised: & 23 September 2021 \\
Accepted: & 23 Oktober 2021
\end{tabular}

\begin{abstract}
Masa perkembangan anak adalah suatu kondisi dimana mereka akan

berubah dari waktu ke waktu. Perubahan ini bisa berbentuk sikap, kepribadian, atau psikologisnya. Agar perkembangan anak tidak terhambat, orang tua dan guru sangat dibutuhkan untuk membimbing mereka. Perkembangan ini juga dapat dibentuk melalui suatu hubungan atau ikatan melalui interaksi sosial. Misalnya ada suatu interaksi sosial yang terjadi antara anak autis dan anak yang pasif di dalam kelas. Interaksi antara anak autis dengan anak pasif juga merupakan bagian dari proses interaksi yang terjadi di dalam lingkungan sekolah. Namun, interaksi ini seringkali terjadinya miscommunication. Masalah yang di hadapi anak autis adalah masalah komunikasi, sosialisasi, kelainan penginderaan, bermain dan perilaku. Sedangkan masalah anak pasif adalah tidak mau bersosialisasi bahkan cenderung menutup diri. Oleh sebab itu, interaksi ini terkadang menjadi penghambat perkembangan anak dan menimbulkan berbagai persepsi. Lalu, keadaan ini menjadi salah satu daya tarik peneliti untuk mengangkat masalah tentang hubungan interaksi dengan perkembangan anak. Adapun metode penelitian yang digunakan adalah metode kuantitatif secara deskriptif korelasi. Penelitian di lakukan di PAUD Baitul Muttaqien kalideres Jakarta Barat selama 3 (tiga) bulan, yaitu dimulai bulan Juli 2021 sampai dengan bulan Agustus 2021. Populasi dan sampel dalam penelitian ini adalah guru dan anak sebanyak 36 orang. Teknik pengumpulan data yaitu observasi dan kuesioner. Teknik analisis data menggunakan analisis deskriptif dan uji korelasi. Hasil menunjukkan bahwa tidak ada perbedaan secara deskriptif antara interaksi sosial anak autis dengan anak pasif. Dan adanya hubungan antara interaksi sosial dengan perkembangan anak di PAUD Nusa Mandiri Satu Kabupaten Sukabumi.
\end{abstract} Accepted: 23 Oktober 2021

Keywords: Interaksi Sosial, Perkembangan Siswa, Anak Autis, Anak Pasif

(*) Corresponding Author: $\quad$ Supardi, supardi.hamka@gmail.com, +62 85215911419

How to Cite: Juariyah, S. \& Supardi. (2021). Hubungan Interaksi Sosial Dengan Pekembangan Anak Di PAUD Nusa Mandiri Satu Kabupaten Sukabumi (Studi Antara Anak Autis Dengan Anak Pasif). Research and Development Journal of Education, 7 (2), 504-510.

\section{INTRODUCTION}

Masa perkembangan anak adalah suatu kondisi dimana mereka akan berubah dari waktu ke waktu. Perubahan ini bisa berbentuk sikap, kepribadian, atau psikologisnya. Agar perkembangan anak tidak terhambat, orang tua sangat dibutuhkan untuk membimbing mereka (Rahmawati, Juhaeni, Aisah, Kinasih, dan Shibyany, 2019). Namun, ada juga beberapa keadaan biologis yang menghambat perkembangan mereka. Oleh sebab itu, orang tua harus terus menjaga dan memperhatikan mereka secara seksama. Perkembangan anak juga dapat dibentuk di pendidikan formal seperti PAUD. Guru paud dapat membantu anak mengembangkan kepribadian melalui berbagai cara 
yang telah ia pelajari. Menurut Gunadi (2013); Khaironi (2017), ada 10 hal penting yang harus diperhatikan dan dijadikan prinsip dalam mengembangkan karakter anak dalam keluarga moralitas penghormatan seperti penghormatan kepada diri sendiri untuk mencegah agar diri sendiri tidak terlibat dalam perilaku yang merugikan diri sendiri, penghormatan kepada sesama manusia meskipun berbeda suku, agama, kemampuan ekonomi, penghormatan kepada lingkungan fisik yang merupakan ciptaan Tuhan, dan perkembangan moralitas kehormatan berjalan secara bertahap. Oleh karena itu, guru harus memperhatikan beberapa hal, yaitu memperlakukan anak didik dengan kasih sayang, adil, dan hormat, memberikan perhatian khusus secara individual agar guru dapat mengenal secara baik anak didiknya, menjadikan dirinya sebagai contoh atau tokoh panutan, membetulkan perilaku yang salah pada anak didik. Perkembangan ini juga dapat dibentuk melalui suatu hubungan atau ikatan.

Interaksi sosial merupakan hubungan yang dinamis menyangkut hubungan antara orang-orang perorangan, antara kelompok-kelompok manusia, maupun antara orang perorangan dengan kelompok manusia. Interaksi sosial merupakan syarat utama terjadinya aktivitas-aktivitas sosial. Ada dua syarat yang harus di penuhi agar suatu interaksi sosial itu mungkin terjadi, yaitu adanya kontak sosial (social contact) dan adanya komunikasi. Proses interaksi sosial tentu berpengaruh terhadap perkembangan anak, baik di sekolah maupun di dalam lingkungan keluarga dan masyarakat. Misalnya ada suatu interaksi sosial yang terjadi antara anak autis dan anak yang pasif di dalam kelas.

Penyandang tuna autistik yang di kenal dengan istilah autisme adalah kombinasi dari berapa kelainan perkembangan otak. Adjeng dan Hatta (2019) mengartikan autis merupakan suatu kondisi dimana anak menunjukkan gangguan yang ditandai oleh terganggunya kognisi sosial, keterampilan sosial, dan interaksi sosial. Ciri ini semakin jelas dengan bertambahnya umur. Pada sebagian kecil lainnya dari individu penyandang autism, perkembangannya terjadi secara normal. Dengan demikian, maka sering ditemukan ciri-ciri yang tumpang tindih dengan beberapa gangguan perkembangan lain. Gradasi manifestasi gangguan juga sangat lebar antara yang berat hingga yang ringan. Di satu sisi, ada individu yang memiliki semua gejala, dan di sisi lain ada individu yang memiliki sedikit gejala. Oleh karena itu. kondisi anak autis yang mengalami masalah perkembangan kompleks sangat membutuhkan penanganan khusus dalam proses interaksi.

Interaksi antara anak autis dengan anak pasif juga merupakan bagian dari proses interaksi yang terjadi di dalam lingkungan sekolah. Namun, interaksi ini seringkali terjadinya miscommunication. Masalah yang di hadapi anak autis adalah masalah komunikasi, sosialisasi, kelainan penginderaan, bermain dan perilaku. Sedangkan masalah anak pasif adalah tidak mau bersosialisasi bahkan cenderung menutup diri. Oleh sebab itu, interaksi ini terkadang menjadi penghambat perkembangan anak dan menimbulkan berbagai persepsi. Lalu, keadaan ini menjadi salah satu daya tarik peneliti untuk mengangkat masalah tentang hubungan interaksi dengan perkembangan anak. Hubungan antara interaksi dengan perkembangan anak akan dikaji secara deskriptif untuk mengambarkan lebih jauh tentang perbedaan antara anak autis dan anak pasif di pendidikan formal PAUD.

\section{METHODS}

Adapun metode penelitian yang digunakan adalah metode kuantitatif secara deskriptif korelasi. Penelitian di lakukan di PAUD Baitul Muttaqien kalideres Jakarta Barat selama 3 (tiga) bulan, yaitu dimulai bulan Juli 2021 sampai dengan bulan Agustus 
2021. Populasi dan sampel dalam penelitian ini adalah guru dan anak sebanyak 36 orang. Teknik pengumpulan data yaitu observasi dan kuesioner. Teknik pengumpulan data yang dilakukan rnelalui daftar pertanyaan yang disusun sedemikian rupa sehingga dapat dengan mudah dijawab oleh para responden, adapun yang menjadi responden ialah para guru dan anak di PAUD Nusa Mandiri Satu Kab. Sukabumi, Cirendeu. Sifat dari observasi dan kuesioner yang diajukan ialah pertanyaan tertutup, yaitu pertanyaanpertanyaan yang variasi jawabannya sudah di tentukan dan di susun terlebih dahulu sehingga para responden hanya memilih jawaban yang telah disediakan. Observasi dan kuesioner telah di uji validitas dan uji reliabilitas untuk dapat digunakan secara sah dan dapat dipercaya. Teknik analisis data menggunakan analisis deskriptif dan uji korelasi.

\section{RESULTS \& DISCUSSION} ini:

Hasil deskripsi dari variabel perkembangan anak dapat dilihat pada tabel berikut

Tabel 1.

Data Statistik Variabel Perkembangan Anak

\begin{tabular}{lrr}
\hline $\mathrm{N}$ & $\begin{array}{c}\text { Valid } \\
\text { Missing }\end{array}$ & 36 \\
& & 65.0556 \\
\hline Mean & 1.16288 \\
Std. Error of Mean & 64.0000 \\
Median & 75.00 \\
Mode & 6.97729 \\
Std. Deviation & 48.683 \\
Variance & -.244 \\
Skewness & .393 \\
Std. Error of Skewness & -.161 \\
Kurtosis & .768 \\
Std. Error of Kurtosis & 27.00 \\
Range & & 48.00 \\
Minimum & & 75.00 \\
Maximum & & 2342.00 \\
Sum & 60.3333 \\
Percentiles & 25 & 64.0000 \\
& 50 & 71.3333
\end{tabular}

Sumber: Output SPSS yang diolah Peneliti (2021)

Berdasarkan hasil deskriptif diatas diketahui bahwa nilai mean dari variabel perkembangan anak adalah 65,1 , nilai median 64 , nilai mode 75 , standar deviasi 6,9 , range 27 , nilai minimum 48 , dan nilai maksimum 75 . Untuk mempermudah mempersentasekan nilai dan menjelaskan hasil output uji deskriptif. Diperlukan data rincian yang dapat dilihat pada tabel 2 berikut ini. 
Tabel 2.

Data Rincian Statistik Deskriptif Variabel Perkembangan Anak

\begin{tabular}{ccccc}
\hline Valid & Frequency & Percent & Valid Percent & Cumulative Percent \\
\hline 48.00 & 1 & 2.8 & 2.8 & 2.8 \\
50.00 & 1 & 2.8 & 2.8 & 5.6 \\
58.00 & 2 & 5.6 & 5.6 & 11.1 \\
59.00 & 1 & 2.8 & 2.8 & 13.9 \\
60.00 & 5 & 13.7 & 13.7 & 27.8 \\
61.00 & 4 & 11.1 & 11.1 & 38.9 \\
63.00 & 3 & 8.3 & 8.3 & 47.2 \\
64.00 & 2 & 5.6 & 5.6 & 52.8 \\
65.00 & 2 & 5.6 & 5.6 & 48.3 \\
66.00 & 1 & 2.8 & 2.8 & 61.1 \\
67.00 & 1 & 2.8 & 2.8 & 63.9 \\
68.00 & 1 & 2.8 & 2.8 & 66.7 \\
69.00 & 1 & 2.8 & 2.8 & 69.4 \\
70.00 & 1 & 2.8 & 2.8 & 72.2 \\
71.00 & 1 & 2.8 & 2.8 & 75.0 \\
72.00 & 2 & 5.6 & 5.6 & 80.6 \\
73.00 & 1 & 2.8 & 2.8 & 83.3 \\
75.00 & 6 & 16.7 & 16.7 & 100.0 \\
Total & 36 & 100.0 & 100.0 & \\
\hline Sumber: Output SPSS yang diolah Peneliti $(2021)$ &
\end{tabular}

Berdasarkan data tabel diatas dapat dijelaskan bahwa nilai median adalah 64 yang merupakan penentu batas atas atau batas bawah. Nilai median 64 menjelaskan batas perkembangan anak. Perkembangan anak ini akan dibagi menjadi dua yaitu perkembangan anak rendah dan perkembangan anak tinggi atau perkembangan anak yang terhambat atau perkembangan anak yang tidak terhambat. Dari data tabel diketahui bahwa 19 anak termasuk dalam perkembangan anak rendah atau perkembangan anak yang terhambat. Dan 17 anak lainnya termasuk dalam perkembangan anak tinggi atau perkembangan anak yang tidak terhambat. Sehingga dapat disimpulkan bahwa perbandingan perkembangan anak lebih banyak pada kategori yang terhambat atau perkembangan anak yang rendah dengan perbandingan 19:17.

Lalu hasil deskripsi dari variabel interaksi sosial anak dapat dilihat pada tabel berikut ini: 
Tabel 3.

Data Statistik Variabel Interaksi Sosial

\begin{tabular}{|c|c|c|}
\hline \multirow[t]{2}{*}{$\mathrm{N}$} & Valid & 36 \\
\hline & Missing & 0 \\
\hline \multicolumn{2}{|l|}{ Mean } & 66.0833 \\
\hline \multicolumn{2}{|c|}{ Std. Error of Mean } & 1.19282 \\
\hline \multicolumn{2}{|c|}{ Median } & 66.6000 \\
\hline \multicolumn{2}{|l|}{ Mode } & 61.00 \\
\hline \multicolumn{2}{|c|}{ Std. Deviation } & 7.15691 \\
\hline \multicolumn{2}{|c|}{ Variance } & 51.221 \\
\hline \multicolumn{2}{|l|}{ Skewness } & -.837 \\
\hline \multicolumn{2}{|c|}{ Std. Error of Skewness } & .393 \\
\hline \multicolumn{2}{|c|}{ Kurtosis } & .759 \\
\hline \multicolumn{2}{|c|}{ Std. Error of Kurtosis } & .768 \\
\hline \multicolumn{2}{|c|}{ Range } & 29.00 \\
\hline \multicolumn{2}{|l|}{ Minimum } & 46.00 \\
\hline \multicolumn{2}{|l|}{ Maximum } & 75.00 \\
\hline \multicolumn{2}{|l|}{ Sum } & 2379.00 \\
\hline \multirow[t]{3}{*}{ Percentiles } & 25 & 61.5000 \\
\hline & 50 & 66.6000 \\
\hline & 75 & 72.0000 \\
\hline
\end{tabular}

Sumber: Output SPSS yang diolah Peneliti (2021)

Berdasarkan hasil deskriptif diatas diketahui bahwa nilai mean dari variabel interaksi sosial adalah 66,1, nilai median 66,6 , nilai mode 61 , standar deviasi 7,2 , range 29 , nilai minimum 46 , dan nilai maksimum 75 . Untuk mempermudah mempersentasekan nilai dan menjelaskan hasil output uji deskriptif. Diperlukan data rincian yang dapat dilihat pada tabel 4 berikut ini.

Tabel 4.

Data Rincian Statistik Deskriptif Variabel Interaksi Sosial

\begin{tabular}{ccccc}
\hline Valid & Frequency & Percent & Valid Percent & Cumulative Percent \\
\hline 46.00 & 1 & 2.8 & 2.8 & 2.8 \\
49.00 & 1 & 2.8 & 2.8 & 5.6 \\
56.00 & 1 & 2.8 & 2.8 & 8.3 \\
59.00 & 2 & 5.6 & 5.6 & 13.9 \\
61.00 & 6 & 16.7 & 16.7 & 30.6 \\
63.00 & 2 & 5.6 & 5.6 & 36.1 \\
64.00 & 1 & 2.8 & 2.8 & 38.9 \\
65.00 & 1 & 2.8 & 2.8 & 41.7 \\
66.00 & 3 & 8.3 & 8.3 & 50.0 \\
67.00 & 2 & 5.6 & 5.6 & 55.6 \\
68.00 & 1 & 2.8 & 2.8 & 58.3 \\
69.00 & 2 & 5.6 & 5.6 & 63.9 \\
70.00 & 2 & 5.6 & 5.6 & 69.4 \\
71.00 & 1 & 2.8 & 2.8 & 72.2 \\
72.00 & 2 & 5.6 & 5.6 & 77.8 \\
74.00 & 4 & 11.1 & 11.1 & 88.9 \\
\hline
\end{tabular}




\begin{tabular}{ccccc}
\hline 75.00 & 4 & 11.1 & 11.1 & 100.0 \\
Total & 36 & 100.0 & 100.0 & \\
\hline \multicolumn{5}{l}{ Sumber: } \\
Output SPSS & yang diolah Peneliti $(2021)$ &
\end{tabular}

Berdasarkan data tabel diatas dapat dijelaskan bahwa nilai median adalah 66,6 yang merupakan penentu batas atas atau batas bawah. Nilai median 66,6 menjelaskan batas interaksi sosial. Interaksi sosial ini akan dibagi menjadi dua yaitu interaksi sosial aktif dan interaksi sosial pasif atau interaksi sosial rendah atau interaksi sosial tinggi. Dari data tabel diketahui bahwa 18 anak termasuk dalam interaksi sosial pasif atau interaksi sosial yang rendah. Dan 18 anak lainnya termasuk dalam interaksi sosial aktif atau interaksi sosial yang tinggi. Sehingga dapat disimpulkan bahwa perbandingan antara anak yang berinteraksi sosial secara aktif dan pasif adalah sama.

Berdasarkan hasil uji korelasi didapat hasil bahwa ada hubungan interaksi sosial dengan pekembangan anak di Paud Nusa Mandiri Satu Kabupaten Sukabumi. Adanya hubungan interaksi sosial dengan perkembangan anak dikarenakan interaksi sosial merupakan salah satu aspek penting untuk perkembangan anak (Iskandar dan Indaryani, 2020). Interaksi sosial ini seperti bersikap kooperatif dengan teman, menunjukkan sikap toleran, memahami peraturan dan disiplin, menunjukkan rasa empati (Latifah dan Sagala, 2014). Hubungan hubungan interaksi sosial dengan pekembangan anak di Paud Nusa Mandiri Satu Kabupaten Sukabumi juga bersifat positif. Artinya, apabila interaksi sosial tinggi maka perkembangan anak juga menajadi tinggi. lalu, apabila interaksi sosial rendah maka perkembangan anak juga menajadi rendah.

\section{CONCLUSION}

Dari hasil penelitian dan pembahasan yang telah dikemukakan maka diperoleh kesimpulan sebagai berikut :

1. Diketahui bahwa 19 anak termasuk dalam perkembangan anak rendah atau perkembangan anak yang terhambat. Dan 17 anak lainnya termasuk dalam perkembangan anak tinggi atau perkembangan anak yang tidak terhambat. Sehingga dapat disimpulkan bahwa perbandingan perkembangan anak lebih banyak pada kategori yang terhambat atau perkembangan anak yang rendah.

2. Diketahui bahwa 18 anak termasuk dalam interaksi sosial pasif atau interaksi sosial yang rendah. Dan 18 anak lainnya termasuk dalam interaksi sosial aktif atau interaksi sosial yang tinggi. Sehingga dapat disimpulkan bahwa perbandingan antara anak yang berinteraksi sosial secara aktif dan pasif adalah sama.

Saran yang dapat penulis sampaikan dalam penelitian semoga dapat menjadi pertimbangan bagi sekolah pada umumnya dan PAUD Nusa Mandiri Satu Kabupaten Sukabumi khususnya. Adapun saran tersebut adalah :

1. Memberikan gambaran kepada pembaca khususnya calon guru tentang hubungan interaksi sosial anak autis dengan anak pasif terhadap perkembangan anak

2. Untuk meningkatkan kecerdasan berinteraksi seorang anak, guru dan keluarga harus memegang peranan penting dalam mendukung proses perkembangan ini.

3. Hendaknya pengawasan dilakukan berdasarkan atas ukuran-ukuran atau standar yang obyektif yang telah ditentukan sebelumnya.

4. Sekolah hendaknya meningkatkan sarana dan prasarana pendidikan sesuai dengan standar pelayanan minimal yang telah ditetapkan oleh departemen pendidikan nasional 
5. Sekolah harus memiliki komitmen untuk meningkatkan profesionalisme guru demi membina interaksi yang positif antara guru dengan siswa, siswa dengan lingkungannya, dan siswa dengan keluarga dan teman-temanya.

\section{REFERENCES}

Adjeng, J., \& Hatta, I. (2019). Pengaruh Terapi ABA terhadap Interaksi Sosial Anak Autis di SLB Autis Prananda Bandung.

Gunadi, R. A. A. (2013). Membentuk karakter melalui pendidikan moral pada anak usia dini di Sekolah Raudhatul Athfal (RA) Habibillah. Jurnal Ilmiah Widya, 1(2), 8591.

Iskandar, S., \& Indaryani, I. (2020). Peningkatan Kemampuan Interaksi Sosial pada Anak Autis Melalui Terapi Bermain Assosiatif. JHeS (Journal of Health Studies), 4(2), 12-18.

Khaironi, M. (2017). Pendidikan Moral Pada Anak Usia Dini. Jurnal Golden Age, 1(01), $1-15$.

Latifah, U., \& Sagala, A. C. D. (2014). Upaya Meningkatkan Interaksi Sosial Melalui Permainan Tradisional Jamuran Pada Anak Kelompok B Tk Kuncup Sari Semarang Tahun Pelajaran 2014/2015. PAUDIA: Jurnal Penelitian dalam Bidang Pendidikan Anak Usia Dini, 3(2 Oktober).

Rahmawati, A., Juhaeni, J., Aisah, S., Kinasih, A., \& Shibyany, N. (2019). Pengelolaan Kelas Terhadap Siswa Tuna Rungu-Wicara Di Kelompok A1 PGRA Mamba'ul Hisan. JECED: Journal of Early Childhood Education and Development, 1(2), 98103. 